\title{
ECOTURISMO NO RIO PURAQUEQUARA: SUPORTE PARA INCLUSÃO SOCIAL E PROTEÇÃO AMBIENTAL
}

\section{Ecotourism in Puraquequara River: Support for Social Inclusion and Environmental Protection}

\author{
Fagno Tavares de Oliveira \\ Turismólogo, Mestre em Ciências Florestais e Ambientais - UFAM \\ Manaus/AM - Brasil \\ fagnotavares@hotmail.com
}

Ivan Crespo Silva

Prof. Dr. Engenharia Florestal - UFPR

Curitiba/PR - Brasil

ivancrespo@ufpr.br

Jackson Fernando Rego Matos

Prof. Dr. do Programa de Pós-Graduação em Ciências Florestais e Ambientais da Universidade Federal do Amazonas - UFAM

Manaus/AM - Brasil

jacksonrego@ufam.edu.br

Francisco Adilson dos Santos Hara

Prof. Dr. do Programa de Pós-Graduação em Ciências Florestais e Ambientais da Universidade Federal do Amazonas - UFAM

Manaus/AM - Brasil

fhara@ufam.edu.br

Artigo recebido para publicação em 24/09/2009 e aceito para publicação em 31/05/2010

RESUMO: $\quad$ Este artigo enfoca uma breve análise do potencial ecoturístico no rio puraquequara, localizado na área de transição da cidade de Manaus no estado do Amazonas, como suporte para a inclusão social e proteção ambiental nas comunidades residentes no entorno deste rio. Foram avaliadas três comunidades: Igarapé da Floresta, Santa Luzia e São Francisco do Mainã, para coleta de informações foi utilizada a entrevista e a observações do ambiente local (observação direta intensiva). Foram realizadas sessenta entrevistas, levantando informações socioeconômicas, área protegida e turismo. Os resultados obtidos apontam a necessidade de atuação do governo estadual e municipal na localidade para a melhoria na infra-estrutura básica (educação, saúde, segurança, energia, abastecimento de água e transporte), além de um forte trabalho com as comunidades, para compreenderem o funcionamento de áreas protegidas e o seu papel para a conservação ambiental, evidenciando a importância de uma atividade local que possa ser socialmente inclusiva e ambientalmente correta. A atividade de ecoturismo vem a ser promissora e adequada para as comunidades do rio puraquequara em função da sua vertente relacionada com as questões sociais e ambientais de forma a promover o bem-estar local, a utilização dos recursos naturais existentes através da organização comunitária e do planejamento participativo. 
Porém, há a necessidade de inserção de outras atividades que possam promover o inter-relacionamento homem-natureza, sem colocar em risco o desenvolvimento do ecoturismo.

Palavras-chave: Comunidades ribeirinhas. Turismo. Desenvolvimento local.

ABSTRACT: This work focuses on a brief analysis of potential ecotourism in the Puraquequara river, localized in transitions area of the city Manaus in state of Amazonas, as support for social inclusion and environmental communities living in neighborhood of this river. Three communities: Igarapé of Florest, Santa Luzia and São Francisco do Mainã, for information was used to interview and observations of the local environment (Direct Observation Intensive). There were sixty interviews, raising socioeconomics informations, protected areas and tourism. The results indicate the need for action by the state government and the municipal area for improvement in basic infrastructure (education, health, safety, energy, water and transport), and a strong work with communities to understand the functioning of protected areas and their role in environmental conservation, highlighting the importance of local activity that can be socially inclusive and enviromentlly correct. The activity of ecotourism seems to be promising and appropriate for the communities of the Puraquequara river according to its aspects related to social and environmental issues in order to promote local well-being, the use of natural resources through community organization and participatory planning. However, there is a need of other activities that may promote the relationship man-nature, without putting in risk the development ecotourism.

Keywords: Community riparian. Tourism. Local development.

\section{INTRODUÇÃO}

A conservação da biodiversidade tem sido uma das questões cruciais para os países em desenvolvimento, por serem detentores de uma grande e rica diversidade biológica, mas com sérios problemas, dentre eles a pobreza. A utilização do ambiente natural, no cenário mundial tem sido palco de amplas discussões por várias entidades governamentais e não-governamentais, com fins de criar e estabelecer meios para se utilizar os recursos ambientais existentes, proporcionando a proteção e conservação dos recursos naturais.

Desde a década de 70 se discute meios para solucionar o problema da proteção e utilização dos recursos naturais. A grande questão é a contenção da deterioração ambiental e a proteção dos ambientes potencialmente sujeitos à destruição. Assim, a partir de instrumentos legais, foram criadas as "áreas protegidas" com a finalidade de garantir a perpetuação dos recursos em espaços delimitados e caracterizados em termos de diversos fatores do ambiente relacionados às florestas, a rede hidrográfica, a fauna, a geologia, etc.
O estabelecimento de áreas protegidas atualmente ainda se configura como a principal alternativa para conter a degradação da natureza e manter a preservação da biodiversidade, entretanto, a forma como estas áreas foram e tem sido estabelecida, tem resultado em polêmica, em particular pelo seu caráter de exclusão social, no cenário global.

Segundo Diegues (1994, p. 11), a criação de áreas naturais protegidas deve-se a ameaça da expansão urbano-industrial destruidora da natureza, com fins de proteger a vida selvagem ameaçada, também chamada de wilderness, resultando na criação do primeiro Parque Nacional de Yellowstone em 1872.

A visão de natureza intocada, através da criação de unidades de proteção integral, no caso do estabelecimento de "parques", onde o ser humano pudesse apreciar e reverenciar a natureza selvagem parece não ter sido a melhor solução. Conforme Azevedo (2002, p. 23) "pouca ou nenhuma importância se deu ao fato de que estes territórios eram ocupados há séculos por povos nativos $[\ldots]$...

Fatores que também contribuíram para o estabelecimento de unidades de conservação ocorreram 
pela rápida devastação e utilização dos recursos naturais, o estabelecimento de atividades econômicas variadas, a possibilidade de geração de renda com a criação de parques e a grande disponibilidade de fundos internacionais (recursos financeiros) para a conservação e proteção da natureza.

Em virtude do estabelecimento de áreas de proteção integral, principalmente de parques, que excluem a presença de populações humanas em seu interior e os conflitos gerados, começaram a ocorrer vários debates acerca do problema da "ocupação humana" em unidades de conservação. Destaque para a II Conferência das Nações Unidades sobre Meio Ambiente e Desenvolvimento (ECO 92), a publicação dos relatórios Estratégia Mundial para a Conservação da IUCN/WWF (1980), Nosso Futuro Comum (1986), e o notório caso do estabelecimento de reservas extrativistas no estado do Acre, através do movimento seringueiro, que ganhou destaque com o assassinato de Chico Mendes.

Para Pimbert \& Pretty (2000, p. 196), a forma de participação das populações locais no estabelecimento de áreas protegidas, é dividida em estágios. "até a década de 70 a participação era vista como instrumento para se conseguir a submissão do povo aos esquemas de áreas protegidas. [...] Durante a década de 80 a participação foi definida como interesse na proteção dos recursos naturais. [...] na década de 90, a participação está sendo vista por alguns como meio de envolver a população no manejo de áreas protegidas".

No Brasil, grande parte das áreas protegidas criadas entre as décadas de 70 e 80 , foi estabelecida prevendo a ausência de moradores em seu interior. As formas de incorporar estas populações no planejamento e implantação, em sua maior parte se deram pela imposição, como forma de atender as expectativas locais e amenizar possíveis conflitos que pudessem ocorrer, sem um consenso democrático e popular.

O reconhecimento da importância e incorporação do conhecimento local mostra-se peça fundamental, para o desenvolvimento mais centrado em solucionar e propor estratégias para o bom desenvolvimento das áreas naturais, de forma a inserir os principais atingidos com o estabelecimento de áreas protegidas, as comunidades.
Pimbert \& Pretty (2000) evidenciam que quando as pessoas e seu conhecimento passam a ser valorizados, há uma participação mais intensa para o desenvolvimento de alternativas que possam contribuir para a melhoria da qualidade de vida e dos problemas enfrentados, que os próprios denominam de participação interativa onde "as pessoas participam em análises conjuntas que conduzem a planos de ação e a formação de novos grupos locais ou no fortalecimento dos já existentes. Tende a envolver uma metodologia interdisciplinar que busca múltiplas perspectivas e faz uso de um sistemático e estruturado processo de aprendizado. Esses grupos assumem o controle acerca das decisões locais e, então, as pessoas adquirem o interesse em manter as estruturas e práticas”.

A partir da década de 90, ganhou destaque no cenário mundial a nomenclatura "desenvolvimento sustentável", com o surgimento de políticas ambientais, que privilegiam pesquisas e projetos que conciliem desenvolvimento com o meio ambiente, ganhando muitos adeptos, passando a ser visto como a solução para o problema de conciliar o desenvolvimento econômico com a conservação do ambiente natural. De acordo com Silveira (2001, p. 2), "o modelo de proteção aos recursos naturais por meio da exclusão da presença humana passa a ser duramente criticado pelos conflitos que criara em todo o mundo".

A idéia de uso racional dos recursos naturais surge da busca por soluções para o embate sobre a questão da presença de populações humanas em áreas protegidas, e na tentativa de resolver este impasse, propôs-se o "desenvolvimento sustentável" onde se permite a presença destas populações no interior da área protegida, sendo regida por regras em que os moradores estariam subordinados a seguir, isto é, mediante a regulamentação e o controle do uso dos recursos naturais (TEIXEIRA, 2005, p. 52).

A forte contribuição para o uso dos recursos pelas populações veio com a elaboração do relatório Estratégia Mundial para a Conservação (WWF/ IUCN 1980), que parte do princípio de que a conservação dos recursos naturais é imprescindível para se manter a vida e satisfazer as demandas da população atual e das futuras. Logo, a "Conservação é o manejo do uso de organismos e ecossistemas, com o fim de garantir a sustentabilidade desse uso. Além do 
uso sustentável, a conservação inclui proteção, manutenção, reabilitação, restauração e melhoramento de populações (naturais) e ecossistemas" (DIEGUES, 2000, p. 01).

A partir deste debate, começou-se a pensar não só nas populações humanas que já estavam estabelecidas em áreas protegidas, contra os efeitos da exclusão, mas no uso humano destes recursos de forma racional e mais equilibrada, como um meio de garantir o desenvolvimento dessas comunidades a partir da utilização dos recursos florestais.

A região amazônica, principalmente o estado do Amazonas, tem sido um dos destinos brasileiros mais procurados por turistas de diferentes origens, interessados em conhecer suas belezas naturais e culturais. O crescimento da atividade turística, por outro lado, torna relevante à compreensão a respeito da relação estabelecida entre as comunidades locais e a atividade, bem como suas formas de exploração e apropriação dos recursos naturais, além de, sua importância na elaboração de estratégias de conservação da natureza.

O meio ambiente se constitui em matéria-prima para a execução da atividade de turismo, tornando importante a boa qualidade do ambiente, pois muitos visitantes (ecoturistas) procuram por este tipo de espaço, para nutrirem suas ânsias e desejos.

Ruschmann (2004, p. 24) retrata que, o turismo nos espaços naturais não é apenas modismo de uma época e que a opinião pública tem se conscientizado, cada vez mais, da necessidade de se proteger o meio ambiente. Há uma grande motivação pela busca por estes espaços, isto é, pelo contato com o ambiente natural, proporcionando um forte apelo comercial, tornando perigoso a utilização do termo ecoturismo para qualquer atividade realizada no ambiente natural.

As áreas de potencial ecoturístico no Brasil têm diversos problemas e dentre eles se destacam a pobreza das comunidades; a necessidade básica das comunidades não resolvidas; a ausência de visão crítica da realidade; a falta de organização comunitária e um processo de gestão concentrador. Esses problemas se refletem sobre a conservação dos recursos, do turismo, da sustentabilidade e do desenvolvimento local (SOUSA, 1998, p. 239).

Para Boo (2001, p. 37) “a maioria das áreas protegidas não está preparada para esse novo hábito do consumidor. Muitas dessas áreas não foram designadas nem projetadas como locais turísticos, e carecem de fundos e de pessoal para satisfazer as necessidades de um número cada vez maior de viajantes que curtem a natureza". Portanto, são observadas as reais necessidades que se encontram nas áreas protegidas e áreas naturais com potencial turístico, devido a necessidade de planejamento para sua realização respeitando o ambiente.

A região do entorno do rio Puraquequara possui mosaicos florestais e mananciais de grande importância para a capital do estado (Manaus), havendo a necessidade de se compreender a relação estabelecida entre a comunidade presente no local e os recursos naturais disponíveis, a partir de seu próprio entendimento, diante do estabelecimento de uma área protegida na Bacia do Puraquequara. Equacionar de forma equilibrada inclusão social e proteção ambiental é o grande desafio que se apresenta no sentido de proteger o ambiente local, garantindo assim o usufruto do mesmo em bases sustentáveis. Este artigo objetiva apresentar a análise do potencial ecoturístico do rio Puraquequara, como alternativa para desenvolvimento regional sustentável.

\section{MATERIAL E MÉTODOS}

A pesquisa foi baseada inicialmente na análise e revisão da literatura disponível sobre áreas protegidas, comunidades e desenvolvimento local, com um caráter qualitativo e um perfil exploratório e descritivo. Com esta concepção foi realizada a pesquisa exploratória em três comunidades locais que se encontram no entorno do rio Puraquequara (FIGURA 1): Igarapé da Floresta (S02 $58^{\prime} 51.9^{\prime \prime}$ e W59 50'05.2”), Santa Luzia (S0302'01.6” e W5949'28.7') e São Francisco do Mainã (S0302'20.7' e W 59 48'04.38”), utilizando-se da técnica de observação direta intensiva (observação e entrevista).

A iniciativa de realização de um trabalho de pesquisa no Puraquequara foi inspirada em trabalhos realizados no entorno da Reserva Adolpho Ducke, o que aguçou a curiosidade de compreender a forma de utilização daquele espaço pela comunidade lá presente. Com esta premissa foi feita uma sondagem explo-

Sociedade \& N atureza, U berlândia, 22 (2): 283-295, ago. 2010 


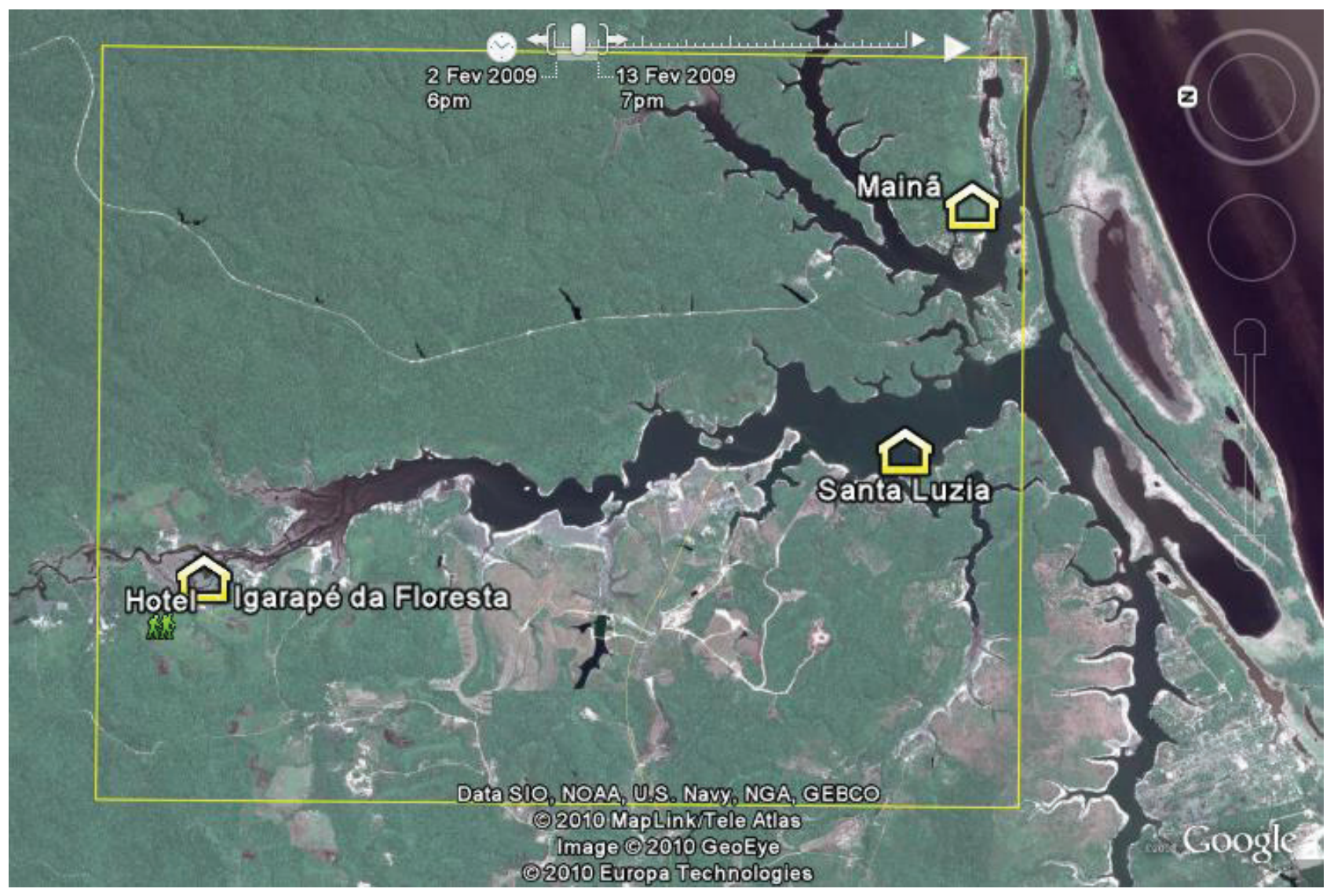

FIGURA 1: Localização das comunidades no rio Puraquequara.

ratória do lugar, visando conhecer o local e a realidade das comunidades, a partir de conversas informais com moradores da região.

O Puraquequara faz parte de uma área de proteção ambiental em processo de estabelecimento, criada pelo Plano Diretor Urbano e Ambiental da Cidade de Manaus no ano de 2002 (unidade de conservação municipal Área de Proteção Ambiental (APA) do Puraquequara), abrange toda a bacia do Rio Puraquequara, em parte incluída em Área de Transição (Lei n ${ }^{\circ}$ 671/2002 - Título III, Cap. I, Art. 42, Inciso I), área que abrange o trabalho desenvolvido.

As comunidades foram visitadas de forma aleatória durante os meses de maio a setembro de 2008 , realizada durante os fins de semana, com intensa participação e observação dos fatos ocorridos nas comunidades. As atividades compreendiam visita a diversos espaços (laboral, lazer e residencial), identificação do tipo de utilização do ambiente, reconhecimento dos atrativos existentes e realização de entrevista (aprovada pelo Comitê de Ética em Pesquisa - CEP/UFAM).

A metodologia utilizada para estudo nas comunidades consistiu na elaboração e realização de entrevista padronizada e semiestruturada para a coleta de informações, que seguiu um roteiro pré-estabelecido nas comunidades (entrevistas: 1 - socioeconômica e 2 - área protegida, turismo e desenvolvimento). A amostragem utilizada foi aleatória simples. No total foram realizadas 59 entrevistas socioeconômicas e 62 sobre área protegida, turismo e desenvolvimento nas comunidades. Valorizando o uso da entrevista em pesquisa de base social Alves-Mazzotti \& Gewandsznajder (1999, p. 168) colocam que "a entrevista permite tratar de temas complexos que dificilmente poderiam ser investigados adequadamente através de questionários, explorando-os em profundidade".

A realização de reunião nas comunidades após a coleta de dados foi proposta para em conjunto de- 
finir pontos em comum e prioridades para seu desenvolvimento, entre os comunitários, isto é, definindo uma escala de prioridade para os fatores internos e externos de forma que possa contribuir para desenvolvimento da comunidade por meio do auxílio da técnica SWOT (Strengths, Weaknesses, Opportunities and Threats), conhecida no Brasil como FOFA (Fortalezas, Oportunidades, Fraquezas e Ameaças). A SWOT tem por objetivo definir estratégias para manter pontos fortes, reduzir a intensidade de pontos fracos, aproveitando oportunidades e protegendo-se das ameaças (AZEVEDO \& COSTA, 2001, p. 2).

Através da identificação de alternativas em conjunto com as comunidades foi feito a avaliação de uma situação desejável para a área. Após a realização das entrevistas (individual) foram enumerados os problemas e as principais atividades sugeridas pelos moradores. Em reuniões realizadas com todos os comunitários foram definidos os problemas que mais os afetam e as principais atividades que gostariam que fossem estabelecidas na comunidade para o seu desenvolvimento.

Foram realizados registros fotográficos, obtenção de coordenadas geográficas através do Sistema de Posicionamento Global (GPS), utilização do software GPS trackmaker e do Google Earth para geração de mapas, gravador portátil para facilitar e dispor na íntegra, sem falhas os depoimentos dos entrevistados. Os dados obtidos com as entrevistas foram tabulados através da confecção de matrizes e analisados mediante estatística descritiva.

\section{RESULTADOS E DISCUSSÃO}

Característica marcante nas comunidades pesquisadas é a exploração dos recursos naturais, havendo o uso mais restrito deste e do espaço na comunidade de São Francisco do Mainã, por estar localizada no interior de uma área pertencente ao Exército Brasileiro - EB, apesar dos comunitários alegarem estar na localidade antes da chegada da Força Armada, os mesmos não possuem documentos que comprovem de fato o direito real a terra.

Nesse aspecto, Arruda (2000, p. 274), ressalta que "as populações tradicionais, em geral ocupam a região há muito tempo, não tem registro legal de propriedade privada individual da terra, definindo apenas o local de moradia como parcela individual, sendo o restante do território encarado como área de uso comunitário, com seu uso regulamentado pelo costume e por normas compartilhadas internamente".

Os dados do perfil socioeconômicos das comu-

TABELA 1: Características gerais das comunidades residentes no entorno do rio Puraquequara.

\begin{tabular}{|c|c|c|c|}
\hline & I garapé da Floresta & Santa L uzia & São Francisco do M ainã \\
\hline $\mathrm{N}^{\circ}$ famílias entrevistadas & 24 & 18 & 17 \\
\hline Profissão & TR/PD/Out. & TR/Pesc/Out. & Pesc/PD \\
\hline Nível Educacional & Ens. Fund. Incom & Ens. Fund. Incom & Ens. Fund. Incom \\
\hline Renda & 1 a 3 salários & 1 a 3 salários & 1 a 3 salários \\
\hline A quisição do local & Compra/D oação & D oação/Compra & Posse \\
\hline Transporte & Fluvial & Fluvial & Fluvial \\
\hline Escola & Ens. Fundamental & Ens. Fundamental & Ens. Fundamental \\
\hline Eletricidade & $\mathrm{G} / \mathrm{L}$ & $E / G$ & G \\
\hline Água & $\mathrm{R} / \mathrm{P}$ & $P / / g / R$ & $P$ \\
\hline Lixo gerado & Q/Ent. & Q & Q \\
\hline Posto de Saúde & Não & Não & Não \\
\hline Economia & $\mathrm{I} / \mathrm{F} / \mathrm{T}$ & I/Pesc/A & Pesc/SG/Ap \\
\hline
\end{tabular}

Abreviaturas: $\mathrm{TR}=$ trabalhador rural, $\mathrm{PD}=$ prendas domésticas, Out $=$ outras, Pesc $=$ pesca, $\mathrm{G}=$ gerador, $\mathrm{L}=$ lamparina, $\mathrm{E}=$ elétrica, $\mathrm{R}=$ rio, $\mathrm{P}=$ poço, $\mathrm{Ig}=$ igarapé, $\mathrm{Q}=$ queima, $\mathrm{Ent}=$ enterra, $\mathrm{I}=$ informalidade, $\mathrm{F}=$ farinha, $\mathrm{T}=$ turismo, $\mathrm{A}=$ agricultura, $\mathrm{SG}=$ serviços gerais, $\mathrm{AP}=$ aposentadoria. 
nidades estão representados na TABELA 1. Os principais animais silvestres e recursos florestais presenciados e utilizados pelos comunitários são observados na FIGURA 2 e QUADRO 1, respectivamente.

$\mathrm{Na}$ questão saúde, o atendimento médico na área ocorre mediante o deslocamento até a Vila do Puraquequara, havendo o atendimento somente as terças-feiras as comunidades de forma precária. Em relação a educação, para conseguir concluir os estudos, os filhos dos comunitários têm que se deslocar ao centro-urbano Manaus, mas há dificuldade para a formação pela disponibilidade financeira baixa e falta de um estabelecimento educacional na localidade que ofereça o ensino médio.

\begin{tabular}{|c|c|c|c|}
\hline Espécie Florestal & Nome científico & Espécie de uso Medicinal & Nome científico \\
\hline Louro & Aritu Licaria aritu Ducke & Carapanaúna & Aspidosperma nitidum Benth. Ex. Mull. Arg. \\
\hline Jacareúba & Calophyllum brasiliense Cambess & Uxi-coroa & Duckesia verrucosa \\
\hline Cedrinho & Erisma uncinatam Warm & Sucuba & Himatanthus sucuuba Woodson. \\
\hline Cupiuba & Goupia glabra Aubl. & Cipó-tuíra & Calycolobus ferrugineus \\
\hline Acariquara & Minquartia guianensis Aubl. & Andiroba & Carapa guianensis AUBL. \\
\hline Angelim & Himenolobium nitidum & Vick & Mentha cf. arvensis L. \\
\hline Itaúba & Mezilaurus itauba (MEISSN) TAUB. & Castanheira & Bertholletia excelsa \\
\hline Castanheira & Bertholletia excelsa & Amapá & Heteropsis off. spruceana Schott. \\
\hline Seringueira & Hevea brasilienses & Caferana & Tachia guianensis AUBL. \\
\hline Maçaranduba & Manilkara huberi (DUCKE) A.CHEV & Jatobá & Hymenaea courbaril L. \\
\hline Cedro & Cedrela fissilis Vell. & Saracura-mirá & Ampelozizyphus amazonicus \\
\hline Tanimbuca & Buchenavia oxycarpa EICHLER & Copaíba & Copaifera officinalis \\
\hline Sucupira & Bowdickia nitida Spruce ex Benth & & \\
\hline Muirapiranga & Brasimun paraense Hub. Maraceae. & & \\
\hline
\end{tabular}

QUADRO 1: Espécies Florestais e de uso Medicinal existentes na região.

Fonte: OLIVEIRA, F.T (2008)

Parte da população estabelecida na área de estudo é proveniente de municípios do interior do estado do Amazonas, vindos em busca de melhores condições de vida no centro metropolitano de Manaus. O tipo predominante de residências são construções totalmente em madeira com poucas residências de alvenaria.

Com relação a atividades agrícolas o cultivo da macaxeira (Manihot utilissima) e da mandioca (Manihot esculenta Crantz) se destaca, principalmente a mandioca para a produção de farinha por ser forne- cedora de renda. Em geral (60,1\%), desenvolvem a atividade agrícola em pequena escala, isto é, a agricultura familiar, compreendendo o cultivo de frutas e verduras em geral, e a criação de pequenos animais para próprio consumo.

$\mathrm{Na}$ comunidade de Igarapé da Floresta, o ecoturismo através da atividade hoteleira tem sido uma das atividades que tem proporcionado geração de renda em maior proporção. Tal fato reforça o que afirma Lindberg \& Huber Jr. (2001, p. 179) sobre a atividade de ecoturismo, "que vem sendo acolhido por muitos 
como uma oportunidade para gerar rendimentos e empregos em áreas relativamente intocadas pelas tentativas tradicionais de desenvolvimento".

Em Igarapé da Floresta, a maioria dos moradores $(70,83 \%)$ utiliza os recursos oriundos da floresta para o próprio consumo, tais como: açaí (Euterpe oleracea Mart.), bacaba (Oenocarpus bacaba Mart.) e buriti (Mauritia flexuosa Mart.); espécies medicinais (casca de sucuba, de castanheira, saracura-mirá, cipótuíra e carapanaúba); além de madeira para fabricação de carvão, reforma de suas residências e da casa de farinha. Na comunidade de Santa Luzia 55,56\% fazem uso do que a natureza oferece, sendo: frutas (bacaba e tucumã); caça de animais; espécies de uso medicinal (casca de carapanaúba, jatobá, raiz de açaí, leite de Amapá, leite de sova, óleo de copaíba e xixuá - Maytenus guianensis); ainda, madeira (para fabricação de carvão e varas). Enquanto que em São Fran- cisco do Mainã, apenas 35,3\% utiliza os recursos naturais, principalmente para uso medicinal, que são o cumarú (Dipteryx odorata (Aubl.) Willd.), jatobá (Hymenaea courbaril L.), uxi-coroa (Endopleura uchi), carapanaúba (Aspidosperma nitidum), sacaca (Croton cajucara Benth.) e uxi-liso (Endopleura uchi), isto se deve, pela presença do Exército no local, restringindo a realização de algumas atividades.

A utilização de frutos como o açaí (Euterpe oleracea Mart.), bacaba (Oenocarpus bacaba Mart.) e buriti (Mauritia flexuosa Mart.), talvez possa fazer parte de sua complementação alimentar, enquanto que, as espécies consideradas medicinais são usadas tanto pela sua efetividade curativa como pela falta de recurso financeiro para comprar medicamentos e pela distância que tem enfrentar para chegar até o posto de saúde mais próximo.

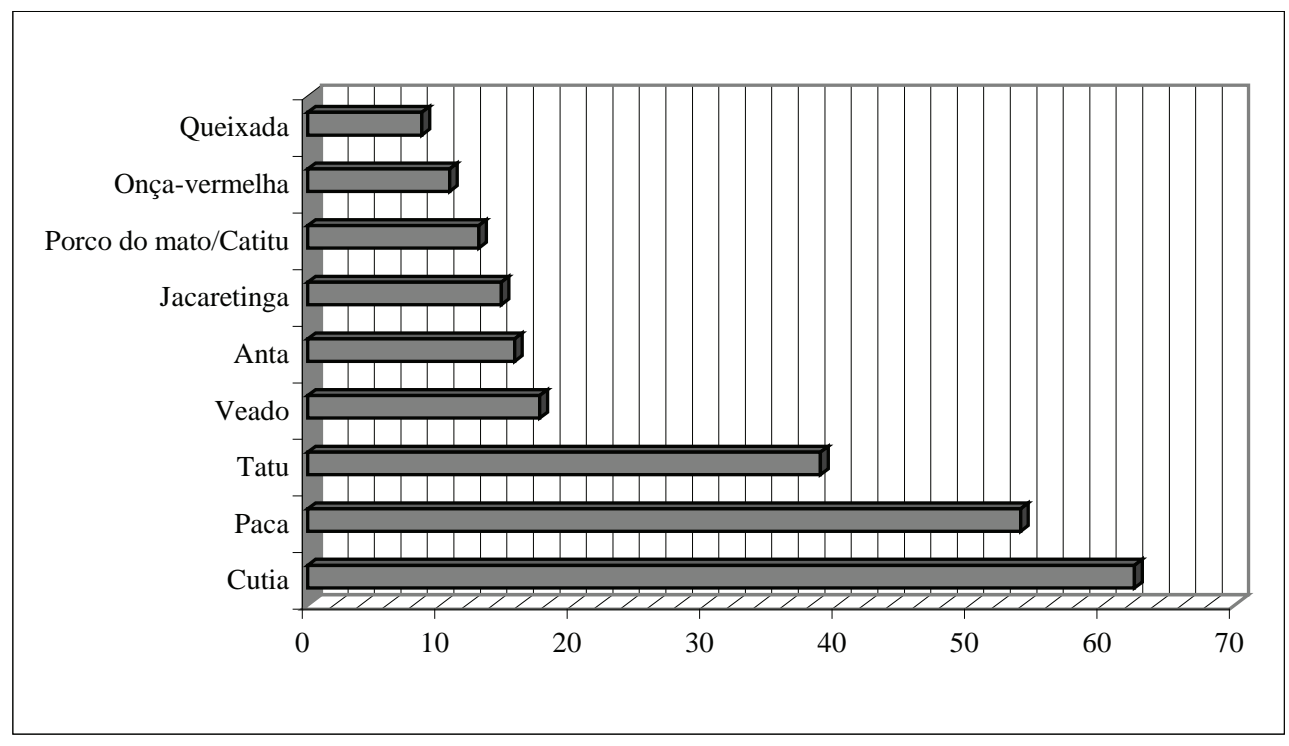

FIGURA 2: Distribuição percentual dos animais silvestres presenciados pelos comunitários.

A floresta se apresenta como fornecedora de insumos para os comunitários, na forma de frutos, madeira, caça e fitoterápicos, contribuindo decisivamente para a sua subsistência. Este contexto está em conformidade com Ribeiro et al. (2007, p. 236) que afirma que "o extrativismo da fauna silvestre para o caboclo amazônico faz da fauna um importante recurso da floresta, visto que, sua exploração constitui-se numa atividade rotineira, sendo importante geradora de renda às populações da região".

Durante este estudo, detectou-se os principais problemas em comum enfrentados nas comunidades, sendo eles: falta de energia $(24,2 \%)$; posto de saúde $(22,2 \%)$; poço artesiano $(15,7 \%)$; trabalho $(5,4 \%)$; escola com ensino médio (5\%). Neste aspecto, $48,8 \%$ dos entrevistados deixavam que estes problemas 
fossem resolvidos pelo presidente da comunidade e $29,8 \%$ sequer esboçavam alguma atitude a respeito. Evidencia-se nesta avaliação, a falta de união e interesse entre os comunitários para solucionar dificuldades comuns.

Quanto à percepção do ambiente local, em relação à área protegida, turismo e desenvolvimento, verificou-se que o conhecimento sobre área protegida pelos entrevistados é superficial, com 77,5\% evidenciando o significado dos termos apenas a "conservar e proteger" a natureza.

Essa localidade, conforme o Plano Diretor, será transformada em uma APA e embora já tenha havido audiência pública sobre o assunto, $51,3 \%$ dos entrevistados não sabem o que significa o assunto, enquanto $48,6 \%$ alegou saber, mas sem uma idéia clara do significado e objetivos de uma área de proteção ambiental. Ficando nítida a falta de esclarecimento e informação sobre este tipo de unidade de conservação, onde poucos a percebem como espaço no qual possa ser feito o uso de forma racional e planejada dos recursos naturais existentes.

Na comunidade de São Francisco do Mainã, alguns acreditam estar em uma área protegida, pois, há certa confusão quando se fala sobre área protegida, devido à presença do Exército no local, necessitando de esclarecimento sobre este aspecto para os comunitários locais.

De um modo geral, evidencia-se nas comunidades avaliadas, a falta de informação sobre os termos proteção e conservação, sendo estes usados como sinônimos, sem que se saiba o real significado das palavras em relação ao o ambiente e as restrições legais correlacionadas. Assim, além dos esclarecimentos que devem receber sobre o assunto, essas populações devem ser, conforme Diegues (2000, p. 43), não somente ouvidas sobre os quesitos da APA, em particular quando da elaboração de estratégias de conservação, como devem dispor de poder deliberativo nos órgãos de decisão. .

Foi avaliado o conhecimento das comunidades sobre área de uso sustentável. Nas três comunidades, a maioria (58\%) desconhece o que seja esta unidade, e $42 \%$ declararam ter algum conhecimento. As informações colhidas fazem menção ao uso da terra, do local, de forma que esta promova o seu sustento. Fica evidente, no caso, a falta de esclarecimento e informação perante o que seja uma área de uso sustentável por parte do órgão responsável pela inserção e gestão da APA. Esta lacuna poderia ser preenchida em oficinas e/ou discussões participativas sobre o que vem a ser uma área protegida e quais os benefícios e restrições que ela pode acarretar.

A criação de uma área protegida na localidade, por parte dos comunitários, é percebida sob duas perspectivas. A primeira mostra receio e desconhecimento sobre a criação de uma área protegida na localidade. Receio, pelo pensamento de que com a criação desta área, ocorra o comprometimento de sua permanência no local, bem como da utilização dos recursos naturais existentes. A segunda está embasada na percepção de benefícios decorrentes do o estabelecimento da área protegida, que segundo esta corrente poderá promover a segurança e fiscalização do local, evitando assim a utilização acelerada dos recursos faunísticos e florestais existentes por parte de pessoas de outras localidades.

A vivência dos entrevistados em seu cotidiano mostra a existência de conflitos e o anseio pela melhoria nas condições de vida atual, a busca de alternativas que saiam do papel e sejam transformados em ações concretas.

Quanto à questão do turismo na localidade, foi avaliado o discernimento dos comunitários sobre a atividade. Os resultados denotam várias percepções vinculadas ao fator turístico, porém com enfoque na maioria das vezes difuso ou indireto. Sendo comum, retratarem o turista como "pessoa que vem conhecer, visitar, viajar, fonte de renda".

Há a prática do turismo na localidade; a comunidade mais afetada com esta atividade é Igarapé da Floresta por estar localizada no entorno do Hotel de Selva, havendo visitas rápidas a estes, principalmente ao roçado, a produção de farinha, o dia-a-dia do ribeirinho, árvores (espécies nativas), casas dos moradores, frutas, animais e as plantas (medicinais e de uso culinário).

A comunidade de São Francisco do Mainã explora indiretamente a atividade, possuindo uma infraestrutura regular para receber os visitantes e alguns atrativos. O principal atrativo desta comunidade é a caminhada pela trilha, onde ocorrem exposições so- 
bre as espécies florestais e medicinais da região, apresentação de técnicas de caça utilizadas pelo caboclo e uma breve parada em um mirante onde se pode vislumbrar o belo cenário de ilhas fluviais e o magnífico encontro das águas (rio Negro e Solimões), prosseguindo deste até o viveiro de peixes, onde o turista pode pescar sua própria alimentação. Há certo descontentamento com os hotéis instalados na região, na abertura de espaço para comunidade receber o turista. Em Santa Luzia, os comunitários relataram haver a prática do turismo, mas que esta é explorada pelo Hotel de Selva instalado na localidade, ficando a cargo deste apresentar o local.

Apesar de ocorrer a exploração da atividade de turismo na região do rio puraquequara pelos hotéis, não há qualquer tipo de parceria estabelecida com as comunidades. Mesmo, não havendo qualquer tipo de parceria com hotéis, há um nível de relacionamento bom das comunidades com a atividade, principalmente por "gerar emprego e renda; pelos turistas conhecerem a realidade local e trazer benefícios".

Poucas são as pessoas que se beneficiam com o turismo, principalmente parte dos moradores da comunidade Igarapé da Floresta, que são mão-de-obra absorvida pelo estabelecimento hoteleiro, sendo o empreendimento apontado como o grande beneficiário. Quanto à participação das comunidades na execução da atividade, em Igarapé da Floresta e Santa Luzia, são apenas coadjuvantes no processo e não sujeitos, representando muitas das vezes, junto aos recursos naturais, "objetos ou fatores" de curiosidade sem terem retorno econômico e social. Somente na comunidade de São Francisco do Mainã, houve um planejamento dos comunitários para definição de execução de tarefas durante a atividade, sendo envolvida uma pequena parcela de moradores.

No entanto, a expectativa quanto ao desenvolvimento do turismo na localidade é percebida como boa pelas comunidades, que, segundo os comunitários, poderá em um primeiro momento favorecer a geração de renda, ficando em segundo plano a conservação da natureza. Neste aspecto, as comunidades anseiam por algo que lhes proporcionem retorno financeiro e no turismo vêem esta possibilidade.

$\mathrm{O}$ ecoturismo poderá ser um dos meios para se conciliar o desenvolvimento local atrelado a conser- vação do ambiente. Entretanto, há a necessidade de capacitação das pessoas interessadas em desenvolver esta atividade, conhecer seus preceitos e objetivos, e o envolvimento com as questões referentes ao ambiente conservado. Pois, o turismo é dependente da qualidade dos recursos naturais para sua perpetuação, que é afirmada por Ruschmann (2004, p. 19) "a inter-relação entre o turismo e o meio ambiente é incontestável, uma vez que este último se constitui a matéria-prima da atividade".

Neste aspecto, têm papel importante o planejamento e gestão para a evolução qualitativa da atividade, de forma a contribuir para a conservação e preservação e atente para as necessidades de um desenvolvimento local mais participativo das populações humanas que residem nessas áreas com características para a exploração e execução do ecoturismo.

\section{Projetos e Propostas de Desenvolvimento Sugeridos pelas Comunidades}

O desenvolvimento de projetos efetivos se torna primordial para as comunidades avaliadas, nelas foi verificada a existência de iniciativas nesse sentido (desenvolvida e/ou em início de desenvolvimento). Na comunidade de Igarapé da Floresta, a maioria dos entrevistados afirmou não haver qualquer tentativa de inserção de programas ou projeto para seu desenvolvimento. Entretanto, uma minoria coloca como projeto a instalação da rede elétrica que foi iniciada, beneficiando parte dos moradores, isto é, sendo realizado metade do previsto e que atualmente se encontra parado.

Enquanto que em Santa Luzia houve a inserção da Piscicultura em tanques redes, através do Instituto de Desenvolvimento Agropecuário do Estado do Amazonas - IDAM, e atualmente está em dificuldades, pela falta de pessoas e de assistência técnica para o desenvolvimento da atividade. Em São Francisco do Mainã foram inseridas a piscicultura e a energia gerada a biodiesel. Somente a piscicultura com a criação de tambaqui e matrinxã em lago natural foi desenvolvido por completo, através do apoio de uma instituição privada, que complementa a renda dos comunitários envolvidos, mas não gera o recurso esperado. Houve nesta comunidade a tentativa de 
desenvolver o projeto de Biodiesel, realizado com incentivos do Governo Federal por meio do Programa Luz para Todos, envolvendo o Instituto Militar de Engenharia - IME, CIGS/CMA, EMBRAPA Amazônia Ocidental e FUCAPI (GONZALEZ, 2006). Deixando esperançosos os moradores, sendo uma frustração aos mesmos, o fato de não ter ocorrido sua finalização, demonstrando falta de planejamento e compromisso com a comunidade.

Grande parte dos comunitários alega que o governo estadual e municipal não contribui para a melhoria da situação local, sendo reiterado que a prefeitura somente tem atuado com a manutenção das escolas e do único posto de saúde localizado na Vila do Puraquequara.

A quase inexistência do poder público na locali- dade faz com que muitos dos moradores desacreditem em qualquer melhoria para suas vidas e no próprio desenvolvimento de projetos. A única participação de pessoas do governo ou da prefeitura no local, em sua maior parte é um "acontecimento de véspera de eleições", o que representa um descontentamento para os comunitários. Este aspecto confirma a assertiva de Kasseboehmer (2007, p. 78) em avaliação de comunidades sob o âmbito de uma Área de Proteção Ambiental (APA) no Paraná "onde a ação política também é citada negativamente entre as causas da queda da qualidade de vida em Guaraqueçaba - PR".

Ao longo da realização desta pesquisa, foi feito o levantamento de quais projetos/atividades estes gostariam que fossem inseridos na localidade (FIGURA 3).

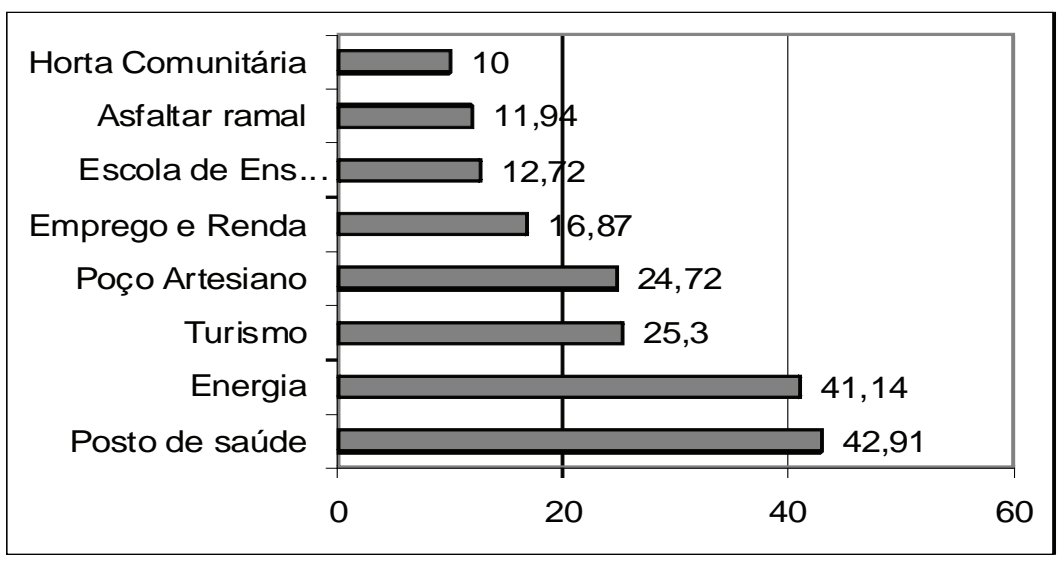

FIGURA 3: Principais sugestões de projetos propostos pelos comunitários (\%).

As respostas mais representativas dos comunitários sobre projetos de desenvolvimento, fazem referência a instalação de um posto de saúde, pela necessidade premente que é aflorada toda vez que um morador da comunidade tem que se deslocar até a Vila do Puraquequara, para tentar atendimento médico, que ocorre somente as terças-feiras para as comunidades ribeirinhas. Este fato cria um descontentamento geral com este serviço, necessário a qualquer tempo.

$\mathrm{O}$ fornecimento de energia ainda é um sonho dos moradores das Comunidades Igarapé da Floresta e São Francisco do Mainã, embora tenha sido iniciada a instalação dos postes e fiação elétrica, para estes a chegada da energia irá contribuir bastante para o local.
No desenvolvimento da atividade de turismo é importante a melhoria das condições físicas e humanas de uma localidade, para receber o visitante. $\mathrm{O}$ estabelecimento da atividade poderá proporcionar melhorias nas condições socioeconômicas e ambientais e poderá favorecer desenvolvimento local participativo.

Os comunitários fazem menção também a um projeto que viabilize a instalação de um poço artesiano que seja da comunidade, não tendo que se preocupar com outros meios para se conseguir água potável. A escola com ensino médio é outro anseio da comunidade, pela falta de condições financeiras em manter o filho (a) estudando na área urbana de Manaus.

$\mathrm{O}$ asfaltamento do ramal na comunidade Igara- 
pé da Floresta é apontado como uma alternativa para a melhora no deslocamento até a área urbana, bem como para facilitar a entrada de transporte no local, para atendimentos emergenciais e para o escoamento da produção. Já a viabilização do capeamento asfáltico favorecerá a perspectiva do turismo nesta região, de forma a colaborar para a promoção da localidade. Por fim, uma horta comunitária, com o objetivo de colaborar tanto para a geração de renda, como para a própria alimentação dos moradores, exigindo assistência técnica para desenvolver este tipo de atividade.

A participação ativa dos comunitários, através da organização da comunidade, é necessária para a melhoria de sua atual condição, pois de forma organizadas terão mais facilidades para participar dos debates e de tomar decisões sobre propostas de desenvolvimento local. Pimberty \& Pretty (2000, p. 207), reforçam este paradigma, "se as comunidades locais realmente participassem das etapas de planejamento, implementação e manutenção dos projetos desenhados para promover saúde, moradia, instalações sanitárias, abastecimento de água e atividades geradoras de renda (como o turismo), então os resultados serão provavelmente mais sustentáveis e efetivos".

\section{CONCLUSÕES}

A participação e envolvimento das populações locais no processo de planejamento e gestão, referentes à criação de unidades de conservação, deve ser considerado como peça-chave para a conservação e proteção do meio ambiente.

A fraca participação das comunidades do rio puraquequara e a ausência da atuação do poder público comprometem a definição e execução de propostas para a preservação e conservação do espaço natural, de ações voltadas para o ambiente, melhoria da infraestrutura e qualidade de vida local.

O turismo pode contribuir para o desenvolvimento regional sustentável em consonância com as comunidades, sendo o segmento ecoturismo alternativa viável para o local. O plano de ação ecoturístico é um instrumento de grande importância para a utilização econômica do local de forma planejada em consonância com a proteção da biodiversidade.

As deficiências na infra-estrutura básica, como falta ou insuficiência de energia elétrica, água potável, transporte e saúde, vem a dificultar qualquer ação do governo e principalmente no desenvolvimento do turismo.

A floresta tem um papel importante para as comunidades ribeirinhas, sendo utilizada diretamente no fornecimento de insumos como caça, frutas e de espécies de uso medicinal para o complemento alimentar e tratamento de enfermidades, tornando importante seu levantamento e manejo.

\section{REFERÊNCIAS}

ALVES-MAZZOTTI, A. J.; GEWANDSZNAJDER, F. O Método nas Ciências Naturais e Sociais: pesquisa quantitativa e qualitativa. 2. ed. São Paulo: Pioneira, 1999.

ARRUDA, R. S. V. "Populações Tradicionais" $e$ a Proteção dos Recursos Naturais em Unidades de Conservação. In: DIEGUES, A. C. (Org.). Etnoconservação: novos rumos para a proteção da natureza nos trópicos. 2. ed. São Paulo: Hucitec: USP, Núcleo de Apoio à Pesquisa sobre Populações, 2000.

AZEVEDO, J. R. R. A conservação da paisagem como alternativa à criação de áreas protegidas: Um estudo de caso do vale do Rio Negro na região do Pantanal - MS. 2002. 122p. Dissertação (Mestrado em Ciência Ambiental) - Programa de Pós-Graduação em Ciência Ambiental. São Paulo: USP, 2002.

AZEVEDO, M. C. \& COSTA, H. G. Métodos para avaliação da postura estratégica. Ensaio. Caderno de Pesquisa em Administração. São Paulo. v. 8, n. 2, abr./ jun. 2001.

BOO, E. O planejamento ecoturístico para áreas protegidas. In: LINDBERG, K.; HAWKINS, D. E. Ecoturismo: um guia para planejamento e gestão. 3. ed. São Paulo: Editora SENAC, 2001.

DIEGUES, A. C. O Mito Moderno da Natureza Intocada. São Paulo: NUPAUB - Universidade de São Paulo, 1994.

Sociedade \& N atureza, U berlândia, 22 (2): 283-295, ago. 2010 
. Etnoconservação da Natureza: Enfoques Alternativos In: DIEGUES, A. C. (Org). Etnoconservação: novos rumos para a proteção da natureza nos trópicos. 2. ed. São Paulo: Hucitec: USP, Núcleo de Apoio à Pesquisa sobre Populações, 2000.

GONZAlEZ, W. A. Primeiro Seminário de Monitoramento dos Projetos Pilotos com Energias Renováveis para Atendimento de Comunidades Isoladas. Instituto Militar de Engenharia. Brasília, 2006.

KASSEBOEHMER, A. L. Restrições e Impactos da Legislação Aplicada no Município de Guaraqueçaba - Paraná. 2007. 144f. Dissertação (Mestrado em Engenharia Florestal) - Programa de Pós-Graduação em Engenharia Florestal da Universidade Federal do Paraná. Curitiba, 2007.

LINDBERG, K. \& HUBER JR, R. M. Questões econômicas na gestão do ecoturismo. In: LINDBERG, K; HAWKINS, D. E. Ecoturismo: um guia para planejamento e gestão. 3. ed. São Paulo: Editora SENAC, 2001.

MANAUS, Prefeitura de. Lei $n^{\circ} 671$, de 04 de novembro de 2002. Regulamenta o Plano Diretor Urbano e Ambiental, estabelece diretrizes para o desenvolvimento da Cidade de Manaus. Prefeitura Municipal de Manaus. Manaus, 2002.

PIMBERT, M. P. \& PRETTY, J. N. Parques, Comunidades e Profissionais: Incluindo "Participação" no Manejo de Áreas Protegidas. In: DIEGUES, A. C. (Org). Etnoconservação: novos rumos para a proteção da natureza nos trópicos. 2. ed. São Paulo: Hucitec: USP, Núcleo de Apoio à Pesquisa sobre Populações, 2000.

RIBEIRO, A. S. S.; PALHA, M. D. C.; TOURINHO, M. M.; WHITEMAN, C. W; SILVA, A. S. L. Utilização dos recursos naturais por comunidades humanas do Parque Ecoturístico do Guamá, Belém, Pára. INPA - ACTA Amazônica. v. 37, p. 235-240. 2007.

RUSCHMANN, D. V. M. Turismo e Planejamento Sustentável: A proteção do meio ambiente. Campinas,
SP: Papirus, 11. ed., 2004.

SILVEIRA, P. C. B. Parks in Peril: People, Politics and Protected Areas. Ambiente \& Sociedade. 4 (9):157-162, 2001.

SOUSA, C. A. A. Ecoturismo e Envolvimento Comunitário. In: VASCONCELOS, F. P. (Org.) Turismo e meio ambiente. Fortaleza: UECE, 1998. PÁGINAS

TEIXEIRA, C. O Desenvolvimento Sustentável em Unidades de Conservação: a "naturalização" do social. Revista Brasileira de Ciências Sociais, v. 20, n. 59, p. 51-66, out. 2005. 